\title{
Produção Animal no Inverno em Capim-Tanzânia Diferido no Outono e Manejado em Diferentes Alturas de Pasto
}

\author{
Marcos Weber do Canto', Ulysses Cecato ${ }^{1}$, Josmar Almeida Júnior², Clóves Cabreira Jobim¹, \\ Renata Alves Agulhon ${ }^{2}$, Vivian Fernanda Gai ${ }^{3}$, André Ricardo Hoeschl², Maria Fernanda Soares Queiroz ${ }^{3}$
}

RESUMO - O experimento foi conduzido com o objetivo de avaliar o ganho médio diário (GMD), número de animais.dia/ha e o ganho de peso vivo (GPV)/ha em uma pastagem de capim-Tanzânia (Panicum maximum Jacq.), diferida em diferentes alturas no outono e após manejada em distintas situações de alturas de pasto, no período do inverno. O delineamento experimental usado foi o inteiramente casualizado. Os tratamentos eram quatro alturas de pasto: $T_{1}=20, T_{2}=40, T_{3}=60$ e $T_{4}=80 \mathrm{~cm}$. No entanto, na análise estatística foram utilizadas as alturas médias de pasto, mantidas em cada unidade experimental, quais sejam: $T_{20} R_{1}=26,3, T_{20} R_{2}=24,6, T_{40} R_{1}=47,9$, $\mathrm{T}_{40} \mathrm{R}_{2}=42,5, \mathrm{~T}_{60} \mathrm{R}_{1}=55,8, \mathrm{~T}_{60} \mathrm{R}_{2}=61,7, \mathrm{~T}_{80} \mathrm{R}_{1}=69,2$ e $\mathrm{T}_{80} \mathrm{R}_{2}=71,4 \mathrm{~cm}$. As diferentes alturas de pasto foram mantidas com o método das lotações contínuas e das cargas variáveis. O GMD reduziu com a elevação da altura da superfície do pasto. Não houve relação significativa entre as diferentes alturas de pasto com o GPV/ha e o número de animais.dia/ha. Os resultados mostram que pastagens de capim-Tanzânia, na região noroeste do Paraná, diferidas após o período reprodutivo, devem ser utilizadas em alturas de pasto de $40 \mathrm{a} 60 \mathrm{~cm}$.

Palavras-chave: ganho médio diário, lotação contínua, manejo do pastejo, Panicum maximum

\section{Winter Animal Production in TanzaniaGrass Deferred in the Autumn and Managed in Different Sward Heights}

\begin{abstract}
The experiment was conducted to evaluate the average daily liveweight gain (ADLG), number of animal.days/ha (AD/ha) and liveweight gain/ha (LG/ha), in a Tanzaniagrass pasture deferred in different sward heights in the autumn and after managed in different sward height conditions, during the winter period. A completely randomized design was used. The treatments were four levels of sward height: $\mathrm{T}_{1}=20, \mathrm{~T}_{2}=40, \mathrm{~T}_{3}=60$ and $\mathrm{T}_{4}=80 \mathrm{~cm}$. However, the average sward height levels maintained in a pasture was used for the statistical analysis, and these were: $\mathrm{T}_{20} \mathrm{R}_{1}=26.3, \mathrm{~T}_{20} \mathrm{R}_{2}=24.6, \mathrm{~T}_{40} \mathrm{R}_{1}=47.9, \mathrm{~T}_{40} \mathrm{R}_{2}=42.5, \mathrm{~T}_{60} \mathrm{R}_{1}=55.8, \mathrm{~T}_{60} \mathrm{R}_{2}=61.7, \mathrm{~T}_{80} \mathrm{R}_{1}=$ 69.2 and $\mathrm{T}_{80} \mathrm{R}_{2}=71.4 \mathrm{~cm}$. The different sward heights were maintained under continuous stocking method and variable stocking rate. The ADLG decreased as the sward height levels increased. There was no effect of sward height with LG/ha and number of animal.days/ha. The results showed that Tanzaniagrass pastures in the northwest region of Paraná, deferred after reproductive phase, could be used in 40 to $60 \mathrm{~cm}$ of sward height.
\end{abstract}

Key Words: average daily liveweight gain, continuous stocking, grazing management, Panicum maximum

\section{Introdução}

A produção de bovinos de corte na região noroeste do Paraná apresenta baixa produtividade. Nessa região, os animais são basicamente alimentados em pastagens, estas sem manejo adequado e em solos de baixa fertilidade. Acrescente-se a isso, a estacionalidade da produção de forragem das pastagens, formadas predominantemente por gramíneas de crescimento estival, ocasionando redução da quantidade e da qualidade da forragem disponível aos animais nos meses do outono, inverno e início da primavera, resultando em baixos desempenhos dos animais.
Pastagens de Panicum maximum apresentam alta capacidade de produção de forragem (Corsi \& Santos, 1995), sendo portanto alternativas para a intensificação da pecuária de corte da região noroeste do Paraná (Hoeschl, 1999). Quanto à produção animal e valor nutritivo, Euclides (1995) mostrou que alguns dos cultivares de Panicum maximum, como o capim-Tanzânia-1, possuem potencial para altas produções de produto animal por unidade de área e apresentam bom valor nutritivo no período de crescimento da primavera e verão.

A disponibilidade de forragem (Rattray et al., 1987) e a altura do pasto (Forbes, 1988) têm sido

${ }^{1}$ Professor do Departamento de Zootecnia da UEM - Campus Universitário - Av. Colombo, 5790, CEP: 87020-900, Maringá - PR. E.mail:ccjobim@uem.br; ucecato@uem.br; mwcanto@uem.br

2 Alunos de Pós-Graduação - PPZ-UEM.

${ }^{3}$ Acadêmicos do curso de Graduação da UEM - Campus Universitário - Av. Colombo, 5790, CEP: 87020-900, Maringá - PR 
usadas no Reino Unido, visando a predição do desempenho por animal. No Brasil, a altura da superfície do pasto não tem sido usada regularmente no manejo de pastagens de gramíneas tropicais. Somente recentemente, e com gramíneas do gênero Cynodon, surgiram estudos sobre o efeito da altura nas características do pasto (Fagundes et al., 1999) e na produção animal (Carnevalli et al., 1999). Em pastagens de azevém perene manejadas sob regime de lotação contínua, Penning et al. (1991) mostraram que o nível de altura do pasto pode ser usado para controlar o consumo e o desempenho por animal de ovinos. Com relação ao período do inverno, os estudos sobre a influência do manejo em Panicum maximum cultivar Tanzânia, utilizando-se a altura do pasto para o manejo do pastejo, ainda são poucos. O conhecimento do efeito da altura do pasto no desempenho de bovinos de corte é de importância, pois é uma forma de se realizar o manejo do pastejo, fácil e prática, podendo ser aplicada nos mais diferentes sistemas de produção que utilizam o capim-Tanzânia.

O presente trabalho faz parte de uma série de experimentos, e visou estudar uma nova proposta de manejo para o capim-Tanzânia. Essa alternativa, incluiu o diferimento (mês de maio), após o período reprodutivo da pastagem, em aproximadamente 70 dias. A prática do diferimento visou, principalmente, permitir o rebrote de lâminas de folhas verdes, para melhorar a qualidade da forragem disponível. $\mathrm{Na}$ região noroeste do Paraná, verificam-se normalmente precipitações próximas ou superiores a $100 \mathrm{~mm}$ nos meses de maio e junho (Nery et al., 1996), havendo também, para a maioria dos anos, condições de temperatura e luminosidade que permitem o crescimento em pastos de capim-Tanzânia.

A hipótese formulada é a de que a altura do pasto influencia a produção animal em capim-Tanzânia, após o diferimento e manejados em regime de lotação contínua, havendo um nível de altura de pasto a ser recomendado para o pastejo de bovinos, nos meses em que a escassez de forragem é mais acentuada.

O presente experimento considera os efeitos e as implicações do manejo do capim-Tanzânia em diferentes alturas e do diferimento realizado após o período reprodutivo da pastagem, quanto ao desempenho por animal, ganho de peso vivo por unidade de área, taxa de lotação e quantidade e qualidade da forragem disponível. Procura relacionar também algumas alterações nas características do pasto, em função do manejo imposto, às diferenças no desempenho por animal.

\section{Material e Métodos}

O experimento foi realizado em área experimental da Fazenda Nossa Senhora Aparecida, localizada no Município de Astorga, Região Noroeste do Paraná. Os resultados da análise do solo, tipo climático da região, bem como as diversas características do pasto foram descritas no trabalho Canto et al. (2001). A área apresenta oito unidades experimentais variando de 1,04 a 1,27 ha, com área adjacente de cinco hectares, também de capim-Tanzânia e destinada aos animais reguladores que participaram do experimento.

O delineamento foi inteiramente casualizado, com duas repetições. Os tratamentos foram quatro alturas de pasto: 20, 40,60 e $80 \mathrm{~cm}$. Para a análise estatística, no entanto, foram usados os níveis médios de altura de pasto mantidos nas diversas unidades experimentais, e estes foram: $26,3 \mathrm{~cm}$ para a repetição um da altura de $20 \mathrm{~cm}(\mathrm{~T} 20 \mathrm{R} 1=26,3), \mathrm{T} 20 \mathrm{R} 2=24,6, \mathrm{~T} 40 \mathrm{R} 1=$ $47,9, \mathrm{~T} 40 \mathrm{R} 2=42,5, \mathrm{~T} 60 \mathrm{R} 1=55,8, \mathrm{~T} 60 \mathrm{R} 2=61,7$, $\mathrm{T} 80 \mathrm{R} 1=69,2$ e T80R $2=71,4 \mathrm{~cm}$.

No período de 19/12/1998 a 13/05/1999, a área experimental foi utilizada em experimento que estudou diferentes alturas de pasto $(20,40,60$ e $80 \mathrm{~cm})$. Antes do estabelecimento da pastagem, realizado no final de setembro de 1998, foram aplicados a lanço e incorporados $180 \mathrm{~kg} / \mathrm{ha} \mathrm{de} \mathrm{P}_{2} \mathrm{O}_{5}$ e $60 \mathrm{~kg} / \mathrm{ha}$ de $\mathrm{K}_{2} \mathrm{O}$. Ao longo do período de 19/12/1998 a 13/05/1999 foram adicionados $250 \mathrm{~kg}$ de nitrogênio/ha, a lanço e na forma de uréia, em todas as unidades experimentais. No início do mês de dezembro de 1998 foram aplicados $50 \mathrm{~kg}$ de nitrogênio/ha, antes da entrada dos animais na área experimental; após, foram aplicados nos meses de janeiro, fevereiro e março, 80, 70 e $50 \mathrm{~kg} / \mathrm{h}$ a de nitrogênio, respectivamente (Peris, 1999). A partir do dia 13/05/1999 as unidades experimentais foram diferidas, até o dia 23/07/1999, onde se iniciou o presente trabalho. Durante o período experimental, de 23/07 a 18/09/1999, os animais foram suplementados com sal e uréia, fornecidos em saleiros cobertos em quantidades de aproximadamente $200 \mathrm{~g} /$ animal/dia. O método de pastejo utilizado foi o das lotações contínuas, sendo os ajustes da carga animal feitos visando manter os níveis de altura de pasto requeridos em cada unidade experimental. Os animais usados foram novilhos da raça Nelore, em fase de recria, com idade de 10 a 11 meses e de massa corporal média inicial de $250 \mathrm{~kg}$.

A altura do pasto foi estimada com o auxílio de uma fita métrica, fazendo-se 40 medidas em cada

R. Bras. Zootec., v.31, n.4, p.1624-1633, 2002 
unidade experimental. O local em que a régua encostou na lâmina da folha mais alta da estrutura do perfilho, a partir do nível do solo, considerou-se como a altura da superfície do pasto. A quantidade de massa de forragem foi estimada por meio do método da dupla amostragem (Wilm et al., 1944). A equação preconizada por Gardner (1986) permitiu o cálculo da quantidade de massa de forragem/ha. Durante a dupla amostragem, foram retiradas quatro amostras para a determinação da composição morfológica da vegetação. Posteriormente, estas amostras foram separadas manualmente por componente morfológico (lâmina de folha verde, colmo verde e material morto), secos em estufa de ar forçado $\left(60^{\circ} \mathrm{C}\right)$ e determinada a massa seca. O componente material morto incluiu as frações de forragem senescente e os caules amarelecidos. A massa de material morto/ha foi obtida pelo produto do percentual de material morto e massa de forragem/ha. A soma dos percentuais dos componentes morfológicos lâmina de folha verde e colmo verde, multiplicados pela massa de forragem/ ha, permitiu a estimativa da massa de forragem verde/ha. A massa de lâminas de folhas verdes/ha foi obtida pelo produto do percentual de lâmina de folha verde e massa de forragem/ha. Foram colhidos 40 perfilhos, representativos do tamanho médio da população de perfilhos do pasto (cortados ao nível do solo), em cada unidade experimental, para a estimativa da massa seca de perfilhos. A densidade populacional de perfilhos foi estimada por meio de seis amostragens, em locais representativos da condição média do pasto, usando-se um quadro de ferro com área de $0,25 \mathrm{~m}^{2}$. Nessa amostragem, os perfilhos foram classificados e quantificados conforme sua posição ao longo da estrutura (perfilho basilar ou perfilho aéreo) e quanto ao estádio de desenvolvimento (perfilho vegetativo ou perfilho reprodutivo). Foi considerado como perfilho reprodutivo aqueles que apresentavam a inflorescência no topo do perfilho. Perfilhos sem a inflorescência, porém com os entre nós alongados, foram considerados perfilhos em estádio vegetativo. A relação perfilho basilar vegetativo/ perfilho basilar reprodutivo foi obtida dividindo-se a densidade populacional de perfilhos basilares vegetativos pela densidade populacional de perfilhos basilares reprodutivos. A digestibilidade in vitro da matéria seca (DIVMS) foi obtida pelo método de Tilley \& Terry (1963). A proteína bruta (PB) foi determinada segundo a técnica descrita em AOAC (1984). A fibra em detergente ácido (FDA) e fibra em detergente neutro (FDN) foram obtidas conforme as técnicas descritas por Goering \& Van Soest (1971). Foram coletadas cinco amostras de forragem (cortadas o mais próximo possível do solo) de $0,25 \mathrm{~m}^{2}$ de área, semelhantes a condição média do pasto, em cada unidade experimental, para determinação dos percentuais de DIVMS, PB, FDA e FDN nos dias 20/08 e 17/09/1999.

O GMD dos novilhos "testers" foi estimado pela subtração da massa corporal inicial da massa corporal final, após este valor, foi dividido pelo número de dias do período experimental. Os animais foram submetidos a um período de jejum de aproximadamente oito horas, com acesso somente a água, antes das pesagens no início e final do período experimental. O número de animais.dia/ha foi obtido a partir do número médio de animais que foram mantidos em cada unidade experimental, multiplicado pelo número de dias do experimento, após este valor foi dividido pela área da unidade experimental. O GPV/ha foi estimado por meio da multiplicação do GMD dos novilhos "testers" pelo número de animais.dia/ha (Mott \& Lucas, 1952). O consumo de nutrientes digestíveis totais (CNDT)/ha foi estimado conforme o método preconizado por Petersen \& Lucas (1968). O ganho de peso acumulado (GPA) foi obtido a partir da fórmula descrita por Karnezos \& Matches (1991), conforme descrita a seguir:

GPA = peso final dos animais "testers" - peso inicial dos animais "testers".

Os dados foram analisados usando-se o pacote estatístico SAS (SAS, 1990), sendo submetidos a análise de variância e regressão polinomial. O GMD e GPA foram correlacionados (correlação linear simples) com a massa de forragem, massa de forragem verde e massa de lâminas de folhas verdes.

\section{Resultados e Discussão}

Os resultados obtidos de porcentagem de DIVMS, GPV/ha, CNDT/ha, taxa de lotação (UA/ha) e número de animais.dia/ha, podem ser vistos na Tabela 1 . Não houve diferenças significativas entre as diferentes alturas de pasto avaliadas com as variáveis apresentadas na Tabela 1. Pode-se verificar que o coeficiente de DIVMS, médio para as diferentes alturas estudadas, foi de $58,5 \%$. O GPV variou de 135 a $195 \mathrm{~kg} /$ ha nas alturas de pasto de 42,5 e 24,6 cm, e o CNDT, a taxa de lotação e número de animais.dia variaram de 695 a $1051 \mathrm{~kg}$ de matéria seca/ha, 1,8 a 3,2 UA/ha e 177 a 329 animais.dia/ha, respectivamente.

\footnotetext{
R. Bras. Zootec., v.31, n.4, p.1624-1633, 2002
} 
A semelhança nos percentuais de DIVMS dos diferentes tratamentos podem ser explicados pelas proporções elevadas de massa de material morto/ha, em todas as unidades experimentais (Tabela 3). Outro fator que influenciou nos resultados de DIVMS foi a ocorrência de uma geada na fase final do experimento, aumentando a fração amarelecida da massa de forragem. A digestibilidade da forragem avaliada foi a da estrutura das plantas inteiras, e os valores são semelhantes aos resultados de DIVMS obtidos por Machado et al. (1998) no período do inverno, com capim-Tanzânia e na região noroeste do Paraná, porém sob condições de corte. Analisando-se os resultados de DIVMS (Tabela 1) e PB (Tabela 2), constata-se que são valores que podem ser considerados médios. Por outro lado, a literatura mostra que a forragem selecionada pelo animal em pastejo é de melhor qualidade que aquela presente na forragem disponível. A falta de significância na resposta do GPV e CNDT por unidade de área deveu-se, em parte, aos maiores GMD observados nas menores alturas (Tabela 2). Também o monitoramento feito no nível da altura da superfície do pasto contribuiu para a falta de resposta do GPV/ha as diferentes alturas, aqui avaliadas. Inicialmente, foram colocadas nas menores alturas de pasto uma menor densidade de lotação, se comparadas aquelas colocadas nas unidades experimentais das maiores alturas. Com o decorrer do experimento, reduziu-se a densidade de lotação das maiores alturas, visando manter-se os níveis de altura de pasto requeridos, conforme o tratamento. Como conseqüência, esse último procedimento determinou também a falta de diferenças significativas na taxa de lotação e número de animais.dia/ha.
Pela Tabela 1, constata-se que o diferimento pode intensificar a produção animal em pastos de capim-Tanzânia, mesmo em um período considerado como de perdas na produção animal. Se considerarmos as variáveis GPV/ha, taxa de lotação e CNDT/ha, verifica-se a viabilidade de se fazer uso de curtos períodos de diferimento. Deve ser ressaltado, que o experimento foi conduzido justamente nos meses em que o período de estresse hídrico (inverno) na região noroeste do Paraná é mais acentuado (Nery et al., 1996). Mostra também, a possibilidade de se obter GPV/ ha na faixa de 150 a aproximadamente $200 \mathrm{~kg} / \mathrm{ha}$. Estes resultados, se adicionarmos aqueles obtidos no experimento conduzido antes da pastagem ter sido diferida, média de $639 \mathrm{~kg} / \mathrm{ha}$ (Hoeschl, 1999), evidenciam o alto potencial de produção animal por área do capim-Tanzânia e a possibilidade de manter a pastagem sob pastejo em boas condições durante grande parte do ano.

Quanto a taxa de lotação, que variou de 1,8 a 3,2 $\mathrm{UA} /$ ha, pode-se afirmar que o manejo aqui empregado determinou taxas de lotação relativamente elevadas, para o período seco do ano. Porém, parcela dos resultados mostrados na Tabela 1, são dependentes, tanto das condições climáticas predominantes durante o período do diferimento como daquelas que ocorreram durante o período experimental, devido ao efeito destas sobre a forragem em oferta disponível.

$\mathrm{Na}$ Tabela 2 são apresentadas as relações lineares e negativas entre o GMD, GPA e percentual de $\mathrm{PB}$, com as alturas de pasto avaliadas. Na Tabela 2 encontram-se também as relações lineares e positivas entre os percentuais de FDA e FDN, com as diferentes alturas de pasto.

Tabela 1 - Coeficientes de digestibilidade in vitro da matéria seca (DIVMS), ganho de peso vivo (GPV), consumo de nutrientes digestíveis totais (CNDT), taxa de lotação e número de animais.dia/ha

Table 1 - Coefficients of in vitro dry matter digestibility (IVDMD), liveweight gain (LG) per area, consumption of total digestible nutrients (CTDN)/ha, stocking rate and number of animal days

\begin{tabular}{|c|c|c|c|c|c|}
\hline $\begin{array}{l}\text { Altura do pasto } \\
\text { Sward height }\end{array}$ & $\begin{array}{l}\text { DIVMS } \\
I V D M D \\
(\mathrm{~cm}) \\
(\mathrm{cm}) \\
\end{array}$ & $\begin{array}{l}\text { GPV } \\
L G \\
(\%) \\
(\%)\end{array}$ & $\begin{array}{r}\text { CNDT } \\
C T D N \\
(\mathrm{~kg} / \mathrm{ha}) \\
(\mathrm{kg} / \mathrm{ha})\end{array}$ & $\begin{array}{c}\text { Taxa de lotação } \\
\text { Stocking rate } \\
\text { (UA/ha)* } \\
(A U / h a)\end{array}$ & $\begin{array}{c}\text { Animais.dia } \\
\text { Animal days } \\
\text { (número/ha) } \\
\text { (number/ha) }\end{array}$ \\
\hline 24,6 & 60 & 195 & 909 & 2,6 & 252 \\
\hline 26,3 & 56 & 189 & 931 & 2,3 & 219 \\
\hline 42,5 & 61 & 135 & 695 & 1,8 & 177 \\
\hline 47,9 & 65 & 177 & 905 & 2,6 & 248 \\
\hline 55,8 & 56 & 179 & 1020 & 3,0 & 271 \\
\hline 61,7 & 58 & 144 & 767 & 2,1 & 207 \\
\hline 69,2 & 59 & 159 & 1003 & 2,9 & 269 \\
\hline 71,4 & 53 & 160 & 1051 & 3,2 & 329 \\
\hline
\end{tabular}

${ }^{*} 1 \mathrm{UA}=450 \mathrm{~kg}$

R. Bras. Zootec., v.31, n.4, p.1624-1633, 2002 
Tabela 2 - Equações de regresssão, coeficientes de determinação, teste $F$ e coeficientes de variação das variáveis ganho médio diário (GMD), ganho de peso acumulado (GPA), percentual de proteína bruta (PB), percentual de fibra detergente ácido (FDA) e percentual de fibra detergente neutra (FDN), em função dos níveis de altura de pasto do capim tanzânia

Table 2 - Regression equations, determination coefficients, $F$ test and coefficients of variation of the variables average daily liveweight gain (ADLG), cumulative weight gain (CUM), percentage of crude protein (CP), percentage of acid detergent fiber (ADF) and percentage of neutral detergent fiber (NDF), in function of the sward height levels of tanzania grass pasture

\begin{tabular}{|c|c|c|c|c|c|}
\hline $\begin{array}{l}\text { Variável } \\
\text { Variable } \\
\end{array}$ & $\begin{array}{l}\text { Equação } \\
\text { Equation }\end{array}$ & $\begin{array}{l}\mathrm{R}^{2} \\
R^{2} \\
\end{array}$ & $\begin{array}{c}\text { Teste F } \\
\text { F test }\end{array}$ & $\mathrm{P}(\mathrm{p}<0)$ & CV $(\%)$ \\
\hline $\begin{array}{l}\mathrm{GMD}(\mathrm{kg} / \text { animal/dia }) \\
A D L G(\mathrm{~kg} / \text { animal/day })\end{array}$ & $Y=0,98404-0,00583 x$ & 0,77 & 24,13 & 0,0027 & 8,10 \\
\hline $\begin{array}{l}\text { GPA (kg/animal) } \\
C U M(k g / \text { animal })\end{array}$ & $Y=56,10514-0,3326 x$ & 0,77 & 24,29 & 0,0026 & 8,08 \\
\hline $\begin{array}{l}\mathrm{PB}(\%) \\
C P(\%)\end{array}$ & $Y=8,78893-0,05103 x$ & 0,74 & 21,09 & 0,0037 & 8,42 \\
\hline $\begin{array}{l}\text { FDA }(\%) \\
A D F(\%)\end{array}$ & $Y=38,81626+0,1129 x$ & 0,78 & 25,90 & 0,0022 & 2,36 \\
\hline $\begin{array}{l}\mathrm{FDN}(\%) \\
N D F(\%)\end{array}$ & $Y=64,23506+0,0873 x$ & 0,91 & 71,04 & 0,0002 & 0,71 \\
\hline
\end{tabular}

Por meio da equação de regressão, observa-se uma variação no GMD por animal de 0,84 a $0,57 \mathrm{~kg} /$ animal/dia, ocorrendo redução no GMD, à medida em que a altura do pasto aumentou.

Este fato está relacionado, principalmente, ao efeito da estrutura das plantas sobre o consumo de forragem e a idade e qualidade da forragem, dos estratos que foram efetivamente pastejados pelos animais. Prache \& Roguet (1996) e Carvalho (1997) tem mostrado o importante papel que a estrutura do pasto exerce sobre o consumo de forragem de ruminantes em pastejo. Devido às condições do meio ambiente, pastos cultivados de gramíneas tropicais, no período seco, apresentam quantidades elevadas de material senescente e baixa oferta de lâminas de folhas verdes na estrutura dos perfilhos. No presente trabalho, as plantas das maiores alturas de pasto apresentaram grandes deteriorações na sua estrutura, com grande fração dos perfilhos com colmos que apresentavam entre nós alongados, perfilhamento mais esparso e com maior participação de caules grossos em relação às lâminas de folhas, ao passo que nas menores alturas de pasto, os perfilhos eram densamente folhosos, com menor quantidade de colmos com alongamento dos entre nós e lâminas de folhas de idade mais jovem. Pode-se afirmar que os pastos mantidos com maiores alturas (alta oferta de forragem) apresentaram maior dispersão espacial de lâminas de folhas verdes, determinando reduções na ingestão de forragem dos animais. Carvalho et al. (2001a), com capim-Tanzânia e usando borregas, observaram a resposta clássica da massa do bocado em função da altura do pasto. Esta resposta mostra que o aumento na massa do bocado está associado ao aumento da altura do pasto, até atingir uma assíntota. Todavia, nas condições de pastos com alturas elevadas, também aumentaria o tempo necessário para a realização de cada bocado. Segundo Carvalho et al. (2001b), nestas últimas situações, haveriam aumentos nos tempos de manipulação e mastigação da forragem até a deglutição.

Quanto à geada ocorrida na fase final do período experimental, é bem possível que a falta de chuvas manteve ainda, em parte, a qualidade da forragem, não ocorrendo à lixiviação de nutrientes, principalmente das lâminas das folhas que eram verdes e tornaram-se amarelecidas. Outro aspecto a ser considerado, refere-se a idade da forragem consumida pelos animais. Trabalhos realizados em pastagens diferidas de inverno e manejadas em diferentes alturas (Hepp et al., 1996), bem como em pastagem nativa diferida após ser manejada com diferentes ofertas de forragem (Moojen, 1991), mostram a renovação de lâminas de folhas verdes na estrutura dos perfilhos dos pastos mantidos em alturas baixas, ou com baixas quantidades de forragem em oferta, havendo pouco rebrote de folhas nos pastos mantidos com maiores alturas. Isto indica, que os animais nas menores alturas consumiram forragem mais jovem. Fração dos valores verificados de GMD podem ser atribuídos também ao fornecimento do sal mais uréia, embora não tenha sido estimado o consumo deste

R. Bras. Zootec., v.31, n.4, p.1624-1633, 2002 
suplemento. Os resultados de GMD mostram um potencial que ainda não era conhecido no período seco do ano, em pastagens de capim-Tanzânia, e isto está relacionado as condições de clima subtropicais (padrões de chuva e temperatura) da região noroeste do Paraná. Esta é uma região de transição entre a região sul e central do Paraná, onde o regime de chuvas é bem distribuído ao longo do ano, e regiões com estação de chuvas concentradas na primavera e verão, seguido de um período seco durante o outono e inverno. Os dados de precipitação pluviométrica dos meses de maio, junho, julho, agosto e setembro, foram de; $126,5,127,0,100,4,0,0$ e $52,3 \mathrm{~mm}$, e são concordantes com os valores médios observados de precipitações pluviométricas de outros anos nesse período (Nery et al., 1996). Os dados de precipitação pluviométrica foram coletados na Estação metereológica da Universidade Estadual de Maringá, distante aproximadamente $17 \mathrm{~km}$ da área experimental, portanto, devem ser vistos com cautela, pois não se referem a dados coletados na área experimental. Entretanto, pode-se considerar, que as quantidades de chuvas que ocorreram na área experimental tenham sido semelhantes aquelas observadas na Estação de Metereologia da Universidade Estadual de Maringá. Assim, de um ponto de vista prático, para o manejador da pastagem, a combinação de níveis altos de fertilidade no solo, adubação de $250 \mathrm{~kg}$ de nitrogênio/ha no período do verão, padrões de chuva e temperatura e área foliar residual, podem garantir forragem em oferta de qualidade para os animais em pastejo.

Com o aumento da altura da superfície do pasto o GPA se reduziu. Conforme a equação de regressão, mostrada na Tabela 2, o GPA variou de 47,7 a 32,2 kg/ animal. As razões da relação linear negativa entre o GPA e os níveis de altura de pasto aqui avaliados, são as mesmas daquelas descritas para o GMD. A implicação dos resultados observados de GPA é que, no caso da região noroeste do Paraná, pastagens de capim-Tanzânia, quando submetidas a períodos relativamente curtos de diferimento, podem apresentar melhorias na qualidade de forragem e na estrutura das plantas (Canto et al., 2002). Isto indica a possibilidade de novilhos Nelore atingirem peso de abate com idade até pouco inferior a dois anos, se mantidos em pastagens bem adubadas e manejadas de capimTanzânia durante a estação de crescimento, sendo posteriormente no inverno mantidos em pastagens com níveis de altura similares ao deste experimento.

O declínio do percentual de PB e aumento nos teores de FDN e FDA (Tabela 2) podem ser atribuídos às maiores quantidades de colmos e material morto da estrutura das plantas com maiores massa de forragem/ha, à medida que se elevou a altura da superfície do pasto, conforme pode ser verificado na Tabela 3.

As quantidades de massa de forragem/ha, massa de forragem verde/ha e massa de lâminas de folhas verdes/ha são mostradas na Tabela 3 .

As quantidades de massa de forragem foram de $2254 \mathrm{~kg}$ de matéria seca/ha na altura de $24,6 \mathrm{~cm}$ a $5702 \mathrm{~kg}$ de matéria seca/ha na altura de $69,2 \mathrm{~cm}$. Quanto as quantidades de matéria seca de lâminas de folhas verdes, estas variaram de 506 a $888 \mathrm{~kg}$ de matéria seca/ha. Trabalhos realizados com bovinos

Tabela 3 - Massa de forragem, massa de forragem verde, massa de lâminas de folhas verdes e massa de material morto

Table 3 - Forage mass, green forage mass, green leaf lamina mass and dead matter mass

\begin{tabular}{|c|c|c|c|c|}
\hline $\begin{array}{l}\text { Altura de pasto } \\
\text { Sward height }\end{array}$ & $\begin{array}{c}\text { Massa de } \\
\text { forragem } \\
\text { Forage mass }\end{array}$ & $\begin{array}{c}\text { Massa de } \\
\text { forragem verde } \\
\text { Green forage mass }\end{array}$ & $\begin{array}{c}\text { Massa de lâmina } \\
\text { de folha verde } \\
\text { Green lamina leaf mass }\end{array}$ & $\begin{array}{c}\text { Massa de } \\
\text { material morto } \\
\text { Dead matter mass }\end{array}$ \\
\hline$(\mathrm{cm})$ & \multicolumn{4}{|c|}{$\begin{array}{c}(\mathrm{kg} \text { de } \mathrm{MS} / \mathrm{ha}) \\
(\mathrm{kg} \text { of } D M / h a)\end{array}$} \\
\hline 24,6 & 2254 & 852 & 506 & 1402 \\
\hline 26,3 & 2562 & 1009 & 599 & 1553 \\
\hline 42,5 & 3986 & 1494 & 809 & 2492 \\
\hline 47,9 & 3862 & 1463 & 828 & 2399 \\
\hline 55,8 & 4007 & 1509 & 787 & 2498 \\
\hline 61,7 & 4580 & 1663 & 888 & 2917 \\
\hline 69,2 & 5702 & 1638 & 754 & 4064 \\
\hline 71,4 & 5228 & 1839 & 881 & 3389 \\
\hline
\end{tabular}

R. Bras. Zootec., v.31, n.4, p.1624-1633, 2002 
em pastejo, nas condições do Mato Grosso do Sul, com o cultivar de Panicum maximum Colonião, verificaram baixos GMD por animal no período do inverno (Souza et al., 1985; Euclides et al., 1993). No caso da região noroeste do Paraná, conforme observado no presente estudo, o diferimento pode contornar, em parte, a redução no desempenho individual dos animais que normalmente ocorre nesse período. Em função da época do ano, era esperada grande quantidade de massa de material morto/ha, como pode ser observado na Tabela 3 . Ainda quanto às quantidades de forragem em oferta disponíveis, Harvey et al. (2000) afirmam que a distribuição vertical e horizontal da massa de forragem e a composição das espécies, influenciam o comportamento dos animais em pastejo.

$\mathrm{Na}$ Tabela 4 são apresentados os coeficientes de correlação das variáveis GMD e GPA com as variáveis massa de forragem/ha, massa de forragem verde/ha e massa de lâminas de folhas verdes/ha.

As correlações entre o GMD e GPA com a massa de forragem/ha e massa de forragem verde/ha foram significativas e negativas. Entretanto, não se constatou correlação entre o GMD e GPA com a quantidade de massa de lâminas de folhas verdes/ha. Os resultados das correlações mostradas na Tabela 4 foram decorrentes, principalmente, da variação do arranjo espacial das lâminas de folhas verdes e estrutura dos perfilhos, que por sua vez ocasionam diferenças no consumo de forragem. No trabalho de Watfe (1999), realizado na mesma área, durante o período que antecedeu o diferimento, diferentemente, não foi constatada relação significativa entre o GMD de

Tabela 4 - Coeficientes de correlação entre variáveis de desempenho por animal ganho médio diário (GMD) e ganho de peso acumulado (GPA) com as características do pasto massa de forragem $(\mathrm{MF}) / \mathrm{ha}$, massa de forragem verde (MFV)/ha e massa de lâminas de folhas verdes (MLFV)/ha

Table 4 - Coefficients of correlation between variables of gain per animal daily liveweight gain (DLG) and cumulative weight gain (CUM) with sward characteristics forage mass (FM)/ha, green forage mass (GFM)/ha and green leaf lamina mass $(G L L M) / h a$

\begin{tabular}{lccc}
\hline Variáveis & MF & MFV & MLFV \\
Variable & $F M$ & $G F M$ & GLLM \\
\hline GMD & $-0,84^{* *}$ & $-0,80^{*}$ & $-0,60 \mathrm{NS}$ \\
GPA & $-0,84^{* *}$ & $-0,81^{*}$ & $-0,61 \mathrm{NS}$ \\
\hline
\end{tabular}

${ }^{1} \mathrm{NS},{ }^{*} \mathrm{e}{ }^{* *}$ Não significativo e significativo a 5 e $1 \%$ de probabilidade, respectivamente.

R. Bras. Zootec., v.31, n.4, p.1624-1633, 2002 novilhos Nelore em fase de recria com as alturas de pasto estudadas 20, 40, 60 e $80 \mathrm{~cm}$. Ainda com relação ao trabalho de Watfe (1999), verificou-se que às correlações entre o GMD dos novilhos com a massa de forragem/ha e massa de lâminas de folhas verdes/ha não foram significativas. As quantidades de massa de lâminas de folhas verdes no experimento de Watfe (1999), variaram de 889 a $1612 \mathrm{~kg}$ de MS/ha, para as quatro condições de altura de pasto avaliadas naquele trabalho. Portanto, com amplitude de variação nas quantidades de massa de lâminas de folhas verdes superior a verificada no período deste estudo (Tabela 3). Os estudos prévios de Hodgson et al. (1977), Moraes (1991), Penning et al. (1991) e Canto et al. (1999) têm evidenciado a influência das alterações nas características de pastos submetidos a distintas intensidades de pastejo, sobre o desempenho por animal e/ou sobre o consumo de forragem. Basicamente, estes estudos ressaltam que as características da forragem em oferta na pastagem são essenciais para a tomada de decisões no sentido de se procurar predeterminar o GMD de animais em pastejo. Ainda são escassos os trabalhos que investigaram as relações entre as diversas características de pastos de capim-Tanzânia com o desempenho e o consumo de forragem por animal, principalmente no inverno e após período de diferimento. Deve ser considerado que nas menores alturas de pasto, com o avanço do mês de setembro (experimento finalizou no dia 18/09), a massa de forragem das menores alturas estava reduzindo (Canto et al., 2001). Possivelmente, pastos mantidos com menores massas de forragem (baixa altura de pasto) e pastejados no período em que o efeito do déficit hídrico e temperatura são mais acentuados, mesmo aqueles mantidos com alta fertilidade no solo e submetidos a curtos períodos de diferimento, determinariam atrasos, em certo grau, no rebrote dos novos perfilhos no início da estação de crescimento. Contudo, este possível impacto sobre a vegetação do capim-Tanzânia mantida em diferentes alturas de pasto necessitaria ser investigado.

Os resultados obtidos no presente trabalho evidenciam que pastagens de capim-Tanzânia podem ser manejadas de forma a manter cargas animais relativamente altas no período seco, com animais apresentando bons GMD. Quanto as quantidades e qualidade da forragem disponível, que determinam consumos de forragem que permitem atingir ganhos de 0,75 a $0,63 \mathrm{~kg} / \mathrm{animal} / \mathrm{dia}$, como no caso das alturas de pasto mantidas na faixa de 40 a $60 \mathrm{~cm}$, precisa-se 
de mais pesquisas que investiguem o efeito da estrutura das plantas e o comportamento ingestivo dos animais, nos diversos cultivares de Panicum maximum, sobre os fatores que afetam o consumo de forragem. No trabalho realizado por Ludlow et al. (1982), com capim-Setária (Setaria sphacelata) e capim-Pangola (Digitaria eriantha) no período seco, foram usados reguladores de crescimento para alterar a densidade dos pastos, visando obter plantas com maior densidade de lâminas de folhas verdes. Esses autores salientaram as importantes implicações, do ponto de vista do manejo das pastagens, de se conhecer e quantificar a densidade de forragem das estruturas das plantas, em razão de que esta variável afeta o consumo de forragem. Recentemente, Carvalho et al. (2001b) citam que tem-se associado a diminuição do ganho por animal, em ofertas de forragem acima do ótimo, à redução da qualidade de forragem, devido a baixa eficiência de utilização da pastagem e acúmulo de material senescente no perfil do pasto. No entanto, ainda segundo Carvalho et al. (2001b), nas situações de alta oferta de forragem, pastos de capim-Tanzânia apresentam lâminas foliares longas, em consequência, os animais adotariam uma estratégia de pastejo tipo "espaguete" para sua captura, e nesse caso, a diminuição do desempenho dos animais também pode ser causada pela redução no consumo. Considerando que nas alturas de pasto mantidas abaixo de $25 \mathrm{~cm}$ pode começar a ocorrer a degradação do pasto, devido a menor cobertura vegetal (Tabela 3 ), e que nas alturas próximas a $70 \mathrm{~cm}$ observa-se uma grande deterioração na estrutura das plantas; estes fatores evidenciam que pastos de capim-Tanzânia devem ser mantidos em alturas de 40 até $60 \mathrm{~cm}$, no período seco e após terem sido diferidas.
Quanto ao uso da altura do pasto, este experimento confirma que no período do inverno esta alternativa de manejo do pastejo pode ser adotado para o capimTanzânia, visando a predição do desempenho individual dos animais. Entretanto, no caso do período de crescimento, no estudo realizado com diferentes ofertas de forragem de lâminas de folhas verdes de Almeida (1997), com capim-Elefante Anão (porte semelhante ao capim-Tanzânia), verificou-se uma tendência quadrática $(\mathrm{P}<0,1617)$ entre o GMD de novilhos cruza Charolês x Nelore com as ofertas de forragem de lâminas de folhas verdes avaliadas. No trabalho de Almeida (1997), as ofertas de forragem de 3,8; 7,5;10,5 e 14,7 kg de matéria seca de lâminas de folhas verdes/100 $\mathrm{kg}$ de peso vivo/dia condicionaram alturas de pasto de 22,0; 42,4; 61,4 e $67,1 \mathrm{~cm}$, respectivamente.

As relações lineares entre as alturas de pasto com a massa de perfilho, densidade populacional de perfilhos basilares reprodutivos e a relação perfilho basilar vegetativo/perfilho basilar reprodutivo, são mostradas na Tabela 5.

Com o aumento da altura da superfície do pasto a massa de perfilho e a densidade populacional de perfilhos basilares reprodutivos, conforme as equações de regressão, variaram de 0,77 a 1,59 g/perfilho e 4,11 a 27,78 perfilhos $/ \mathrm{m}^{2}$, respectivamente. De acordo com diversos trabalhos, ocorre aumento na massa de perfilho à medida em que eleva-se a altura do pasto. Os perfilhos das maiores alturas são de maior tamanho e massa, com menor relação lâmina de folha verde/colmo verde, e por estas razões, possuem maior participação de material lignificado, alto conteúdo de fibra e carboidratos estruturais, concentrados principalmente nos caules dos estratos

Tabela 5 - Equações de regressão, coeficientes de determinação, teste $F$ e coeficientes de variação das variáveis massa de perfilho (MP), densidade populacional de perfilhos basilares reprodutivos (DPPBR) e relação perfilho basilar vegetativo/perfilho basilar reprodutivo, em função dos níveis de altura de pasto do capimTanzânia

Table 5 - Regression equations, determination coefficients, $F$ test and coefficients of variation (CV) of variables Tiller mass (TM), reproductive basal tiller density (RBTD) and reproductive basal tiller/vegetative basal tiller ratio, in function of the sward height levels of tanzânia grass pasture

\begin{tabular}{lccccc}
\hline $\begin{array}{l}\text { Variável } \\
\text { Variable }\end{array}$ & $\begin{array}{c}\text { Equação } \\
\text { Equation }\end{array}$ & $\begin{array}{c}\mathrm{R}^{2} \\
R^{2}\end{array}$ & $\begin{array}{c}\text { Teste } \mathrm{F} \\
\text { F test }\end{array}$ & $\mathrm{P}(\mathrm{p}<0)$ & $\mathrm{CV}(\%)$ \\
\hline $\begin{array}{l}\text { MP }(\mathrm{g} / \text { perfilho }) \\
\text { TM }(\mathrm{g} / \text { tiller) }\end{array}$ & $\mathrm{Y}=0,3373+0,0175 \mathrm{X}$ & 0,95 & 124,94 & 0,0001 & 6,15 \\
$\begin{array}{l}\text { DPPBR }\left(\mathrm{perfilhos} / \mathrm{m}^{2}\right) \\
\left.\text { RBTD (tiller } / \mathrm{m}^{2}\right)\end{array}$ & $\mathrm{Y}=-9,3858+0,5486 \mathrm{X}$ & 0,77 & 23,82 & 0,0028 & 29,71 \\
$\begin{array}{l}\text { RPBVPBR } \\
\text { RBT/VBTR }\end{array}$ & $\mathrm{Y}=137,91-1,7875 \mathrm{X}$ & 0,82 & 32,73 & 0,0012 & 30,55 \\
\hline
\end{tabular}

R. Bras. Zootec., v.31, n.4, p.1624-1633, 2002 
inferiores da estrutura das plantas. A relação perfilho basilar vegetativo/perfilho basilar reprodutivo diminuiu com o aumento da altura do pasto. Possivelmente, as quantidades médias de perfilhos em estádio reprodutivo, mostradas na Tabela 5 , foram maiores do que as aqui quantificadas, uma vez que parte das inflorescências dos perfilhos teria sido cortada pelo pastejo dos animais.

$\mathrm{Na}$ Tabela 6 são apresentados os resultados de densidade populacional de perfilhos basilares vegetativos, densidade populacional de perfilhos aéreos vegetativos e densidade populacional de perfilhos aéreos reprodutivos. Não foram observadas diferenças entre as variáveis mostradas na Tabela $6 \mathrm{com}$ as diferentes alturas de pasto.

As médias da densidade populacional de perfilhos basilares vegetativos variaram de 370 a 688 perfilhos $/ \mathrm{m}^{2}$. A densidade populacional de perfilhos aéreos em estádio vegetativo variou de 26 a 56 perfilhos $/ \mathrm{m}^{2}$. Observa-se ainda pela Tabela 6, que a densidade populacional de perfilhos em estádio reprodutivo foi menor que a densidade de perfilhos aéreos em estádio vegetativo. Convém salientar, que os perfilhos aéreos tem tamanho muito reduzido, portanto tendo pouca participação, no total da forragem em oferta na pastagem e portanto na forragem que foi consumida pelos animais em pastejo.

Tabela 6 - Densidade populacional de perfilhos basilares vegetativos (DPPBV), densidade populacional de perfilhos aéreos vegetativos (DPPAV) e densidade populacional de perfilhos aéreos reprodutivos (DPAR)

Table 6 - Vegetative basal tiller population density (VBTPD), vegetative aerial tiller population density (VATPD) and reproductive aerial tiller population density (RATPD)

\begin{tabular}{lccc}
\hline $\begin{array}{l}\text { Altura do pasto } \\
\text { Sward height }\end{array}$ & $\begin{array}{r}\text { DPPBV } \\
\text { VBTPD }\end{array}$ & $\begin{array}{c}\text { DPAV } \\
\text { VATPD }\end{array}$ & $\begin{array}{c}\text { DPAR } \\
\text { RATPD }\end{array}$ \\
\hline (cm) & \multicolumn{3}{c}{$\begin{array}{c}\left.\text { (Perfilhos } / \mathrm{m}^{2}\right) \\
\left(\text { Tillers } / \mathrm{m}^{2}\right)\end{array}$} \\
& \multicolumn{3}{c}{ ( $)$} \\
26,3 & 481 & 26 & 1 \\
24,6 & 550 & 30 & 7 \\
47,9 & 631 & 37 & 22 \\
42,5 & 688 & 26 & 9 \\
55,8 & 625 & 46 & 5 \\
61,7 & 441 & 51 & 27 \\
69,2 & 370 & 56 & 31 \\
71,4 & 496 & 49 & 31 \\
\hline
\end{tabular}

R. Bras. Zootec., v.31, n.4, p.1624-1633, 2002

\section{Conclusões}

O ganho médio diário aumenta, nas amplitudes de altura de pasto estudadas, com a redução da altura do pasto.

Não houve correlação entre o ganho médio diário e a massa de lâminas de folhas verdes. Houve correlação entre o ganho médio diário e o ganho de peso acumulado com a massa de forragem e massa de forragem verde.

$\mathrm{Na}$ região Noroeste do Paraná, pastagens de capim-Tanzânia, diferidas após período reprodutivo para serem utilizadas no período do inverno, devem ser mantidas em alturas de pasto de $40 \mathrm{a} 60 \mathrm{~cm}$.

Os pastos mantidos em alturas de 40 e $60 \mathrm{~cm}$ determinaram ganhos médio diário de 0,75 e $0,63 \mathrm{~kg} /$ animal/dia, condicionando ganhos de peso acumulado de 42 e $36 \mathrm{~kg} /$ animal, evidenciando que mesmo no período seco, os animais podem apresentar desempenhos satisfatórios, em função do manejo do pasto conforme a altura e da quantidade e qualidade da oferta de forragem disponível.

\section{Literatura Citada}

ALMEIDA, E.X. Oferta de forragem de capim elefante anão (Pennisetum purpureum Schum cv. Mott), dinâmica de pastagem e sua relação com o rendimento animal no alto Vale do Itajaí, Santa Catarina. Porto Alegre: Universidade Federal do Rio Grande do Sul, 1997. 112p. Tese (Doutorado em Zootecnia) - Universidade Federal do Rio Grande do Sul, 1997.

ASSOCIATION OF OFFICIAL ANALITICAL CHEMISTS AOAC. Official methods of analysis. 14.ed. Washington, D.C.: 1984. $1141 \mathrm{p}$.

CANTO, M.W.; MOOJEN, E.L.; CARVALHO, P.C.F. et al. Produção de cordeiros em pastagens de azevém e trevo branco sob diferentes níveis de resíduos de forragem. Pesquisa Agropecuária Brasileira, v.34, n.2, p.257-278, 1999.

CANTO, M.W.; CECATO, U.; PETERNELLI, M. et al. Efeito da altura do capim-Tanzânia diferido nas características da pastagem no período do inverno. Revista Brasileira de Zootecnia, v.30, n.4, p.1186-1193, 2001.

CANTO, M.W.; CECATO, U.; JOBIM, C.C. et al. Acúmulo de forragem e perfilhamento em capim tanzânia diferido após pastejo em diferentes alturas. Acta Scientiarum, v.24, n.4, prelo, 2002.

CARNEVALLI, R.A.; DA SILVA, S.C.; PEDREIRA, C.G.S. et al. Pasture and animal responses of tifton 85 swards grazed by the sheep under continuous stocking. In: INTERNATIONAL SYMPOSIUM "GRASSLAND ECOPHYSIOLOGY AND GRAZING ECOLOGY”, 1999, Curitiba. Proceedings... Curitiba: Universidade Federal do Paraná, 1999. p.357-361.

CARVALHO, P.C.F. A estrutura da pastagem e o comportamento ingestivo de ruminantes em pastejo. In: SIMPÓSIO SOBRE AVALIAÇÃO DE PASTAGENS COM ANIMAIS, 1997, Maringá. Anais... Maringá: Universidade Estadual de Maringá, 1997. p.25-52. 
CARVALHO, P.C.F.; MARÇAL, G.K.; RIBEIRO FILHO, H.M.N. et al. Pastagens altas podem limitar o consumo dos animais. In: REUNIÃO ANUAL DA SOCIEDADE BRASILEIRA DE ZOOTECNIA, 38., 2001, Piracicaba. Anais... Piracicaba: Sociedade Brasileira de Zootecnia, 2001a. p.265-266.

CARVALHO, P.C.F. Importância da estrutura da pastagem na ingestão e seleçãode dietas pelo animal em pastejo. In: A PRODUÇÃO ANIMAL NA VISÃO DOS BRASILEIROS, 2001, Piracicaba. Anais... Piracicaba: Sociedade Brasileira de Zootecnia, 2001b. p.853-871.

CORSI, M.; SANTOS, P.M. Potencial de produção do Panicum maximum. In: SIMPÓSIO SOBRE MANEJO DE PASTAGENS, 12., 1995, Piracicaba. Anais... Piracicaba: Fundação de Estudos Agrários "Luiz de Queiroz", 1995. p.275-303.

EUCLIDES, V.B.P.; MACEDO, M.C.M.; VIEIRA, A. et al. Evaluation of Panicum maximum cultivars under grazing. In: INTERNATIONAL GRASSLAND CONGRESS, 17 ., 1993, Palmerston North. Proceedings... Palmerston North: New Zealand Grassland Association, 1993. p.1999-2000.

EUCLIDES, V.B.P. Valor alimentício de espécies forrageiras do gênero Panicum. In: SIMPÓSIO SOBRE MANEJO DE PASTAGENS, 12., 1995, Piracicaba. Anais... Piracicaba: Fundação de Estudos Agrários "Luiz de Queiroz", 1995. p.245-273

FAGUNDES, J.L.; SILVA, S.C.; PEDREIRA, C.G.S. Intensidade de pastejo e a composição morfológica de pastos de Cynodon spp. Scentia Agricola, v.56, n.4, p.897-908, 1999.

FORBES, T.D.A. Researching the plant-animal interface: the investigation of ingestive behaviour in grazing animals. Journal of Animal Science, v.66, n.9, p.2369-2379, 1988.

GARDNER, A.L. Técnicas em pesquisa em pastagens e aplicabilidade de resultados em sistemas de produção. Brasília: IICA, Embrapa-CNPGL, 1986. 197p.

GOERING, H.K.; Van SOEST, P.J. Forage fiber Analysis (apparatus, reagents, procedures, and some applications). Washington, D.C.: U.S. Gov. Print. Office. 1971. (Agric. Hanb. 379).

HARVEY, A.; PARSONS, A.J.; ROOK, A.J. Dietary preference of sheep for perennial ryegrass and white clover at contrasting sward surface heights. Grass and Forage Science, v.55, n.3, p.242-252, 2000

HEPP, C.; MILNE, J.A.; ILLIUS, A.W. et al. The effect of summer management of perennial ryegrass-dominant swards on plant and animal responses in the autumn when grazed by sheep. 1. Tissue turnover and sward structure. Grass and Forage Science, v.51, n.3, p.250-259, 1996.

HODGSON, J.; RODRIGUEZ CAPRILES, J.M.; FENLON, J.S. The influence of sward characteristics on the herbage intake of grazing calves. Journal of Agricultural Science, v.89, n.2, p.743-750, 1977.

HOESCHL, A.R. Ganho de peso de novilhos nelore em uma pastagem de capim-tanzânia (Panicum maximum Jacq.) manejada em diferentes alturas de pastagem. Maringá: Universidade Estadual de Maringá, 1999. 22p. Monografia (Graduação em Zootecnia) - Universidade Estadual de Maringá, 1999.

KARNEZOS, T.P.; MATCHES, A.G. Lamb production on wheatgrasses and wheatgrasses-sainfoin mixtures. Agronomy Journal, v.83, n.2, p.278-286, 1991.

LUDLOW, M.M.; STOBBS, T.H.; DAVIS, R. et al. Effect of sward structure of two tropical grasses with contrasting canopies on light distribution, net photosynthesis and size of bite harvested by grazing cattle. Australian Journal of Agricultural Research, v.33, n.2, p.187-201, 1982.

MACHADO, A.O.; CECATO, U.; MIRA, R.T. Avaliação da composição e digestibilidade in vitro da matéria seca de cultivares e acessos de (Panicum maximum Jacq) sob duas alturas de corte. Revista Brasileira de Zootecnia, v.27, n.5, p.1057-1063, 1998.

R. Bras. Zootec., v.31, n.4, p.1624-1633, 2002
MOOJEN, E.L. Dinâmica e potencial produtivo de uma pastagem nativa do Rio Grande do Sul submetida a pressões de pastejo, épocas de diferimento e níveis de adubação. Porto Alegre: Universidade Federal do Rio Grande do Sul, 1991. 172p. Tese (Doutorado em Zootecnia) Universidade Federal do Rio Grande do Sul, 1991.

MORAES, A. Produtividade animal e dinâmica de uma pastagem de capim pangola (Digitaria decumbens Stent), azevém (Lolium multiflorum) e trevo branco (Trifolium repens L.), submetida a diferentes pressões de pastejo. Porto Alegre: Universidade Federal do Rio Grande do Sul, 1991. 200p. Tese (Doutorado em Zootecnia) - Universidade Federal do Rio Grande do Sul, 1991.

MOTT, G.O.; LUCAS, H.L. The design, conduct and interpretation of grazing trials on cultivated and improved pastures. In: INTERNATIONAL GRASSLAND CONGRESS, 6., 1952, Pensylvania. Proceedings... Pensylvania: State College Press, 1952. p.1380-1385.

NERY, J.T.; SILVA, W.C.; MARTINS, M.L.O.F. Aspectos geográficos e estatísticos da precipitação do Estado do Paraná. Revista Unimar, v.18, n.4, p.777-789, 1996.

PENNING, P.D.; PARSONS, A.J.; ORR, R.J. Intake and behaviour responses by sheep to changes in sward characteristics under continuous stocking. Grass and Forage Science, v.46, n.1, p.15-28, 1991.

PERIS, R.S.M. Capacidade de suporte em uma pastagem de capim tanzânia (Panicum maximum Jacq.) submetida a diferentes alturas de pastagem. Maringá: Universidade Estadual de Maringá, 1999. 25p. Monografia (Graduação em Zootecnia) - Universidade Estadual de Maringá, 1999.

PETERSEN, R.G.; LUCAS, H.L. Computing method for the evaluation of pasture by means of animal response. Agronomy Journal, v.60, n.6, p.682-687, 1968.

PRACHE, S.; ROGUET, C. Influence de la structure du couvert sur le comportment d'ingestion. (S.I.): Institut National de la Recherche Agronomique. 1996. p.22-24. (Rapport d'Activité 1992-1995).

RATTRAY, P.V.; THOMPSON, K.F.; HAWKER, H. et al. Pastures for sheep production. In: NICOL, A.M. (Ed.) Feeding livestock on pasture. Hamilton: New Zealand Society of Animal Production, 1987. p.89-103.

SAS INSTITUTE. SAS user's guide: statistics. 4.ed. Cary: 1990.

SOUZA, J.C.; GOMES, R.F.C.; SILVA, J.M. et al. Suplementação mineral de novilhos de corte em pastagens adubadas de capim colonião. Pesquisa Agropecuária Brasileira, v.20, n.2, p.259-269, 1985.

TILLEY, J.M.A.; TERRY, R.A. A two stage technique for the "in vitro" digestion of forage crop. Journal of the British Grassland Society, v.18, n.2, p.104-111, 1963.

WATFE, E. Relação entre o desempenho por animal e características de uma pastagem de capim tanzânia manejada em diferentes alturas de pastagem. Maringá: Universidade Estadual de Maringá, 1999.23p. Monografia (Graduação em Zootecnia) - Universidade Estadual de Maringá, 1999.

WILM, H.G.; COSTELLO, O.F.; KLIPPLE, G.E. et al. Estimating forage yield by the double sampling method. Journal of American Society of Agronomy, v.36, n. 1, p.194-203, 1944.

Recebido em: 26/10/01 Aceito em: 10/05/02 